\title{
Indirect economic costs of avoidable mortality
} in Moldova

\author{
Irina Pahomii ${ }^{1,2, *}$ \\ ${ }^{1}$ Centre for Demographic Research, National Institute for Economic Research, Moldova \\ 2 Department of Demography and Geodemography, Faculty of Science, Charles University, Czechia \\ * Corresponding author: pahomiii@natur.cuni.cz
}

\begin{abstract}
In this article, we carry out the cost-analysis of the total premature mortality and avoidable causes of death for Moldova by applying the human capital approach. The results show that the indirect costs of avoidable mortality represent slightly over $85 \%$ of total economic losses due to premature mortality in Moldova. The highest economic losses are due to injuries, cardiovascular diseases, and alcohol and drug-related deaths. For males, the leading cause is represented by injuries, whereas for females the two leading causes include cardiovascular diseases and alcohol and drug-related deaths. The results of this study can be used for a cost-benefit analysis to design economic mitigation strategies aimed at lowering the avoidable mortality in Moldova.
\end{abstract}

\section{KEYWORDS}

premature mortality; avoidable mortality; causes of death; human capital approach

Received: 20 May 2020

Accepted: 8 December 2020

Published online: 29 January 2021

Pahomii, I. (2021): Indirect economic costs of avoidable mortality in Moldova. AUC Geographica 56(1), 56-64 https://doi.org/10.14712/23361980.2021.1

(C) 2021 The Author. This is an open-access article distributed under the terms of the Creative Commons Attribution License (http://creativecommons.org/licenses/by/4.0). 


\section{Introduction}

The premature mortality is defined by Australian Institute of Health and Welfare as "deaths that occur at an age earlier than a selected cut-off" (Australian Institute of Health and Welfare 2016), in work of Canadian researchers is made an important remark and is stated that "premature mortality refers to people who die of a health condition earlier than expected" (Pham, Shack, Cheung 2019). In this state of ideas premature deaths represent deaths that occur from birth to a set age threshold (Joel 2017). In fact, premature death represents important multi-aspectual losses, not just in term of irrecuperable human life losses, but from the potential economic, creative and social resource point of view.

The more important segment of premature mortality is represented by avoidable mortality. The concept of avoidable mortality refers to deaths that given current medical knowledge and technology, could be prevented, treated or both. So, avoidable deaths are represented by preventable, amenable, or both. The preventable causes of death are causes of death that can be mainly avoided through effective public health and primary prevention interventions. The amenable causes of death are causes of death that can be mainly avoided through timely and effective health care interventions, including secondary prevention and treatment (OECD/Eurostat 2019). The concept of avoidable mortality was used and developed by numerous authors. Because of different conceptualization of avoidable mortality, there are known several lists of preventable or amenable causes of death (Holland 1997; Nolte, McKee 2004; OECD/Eurostat 2019). The last version was presented by OECD in November 2019 (OECD/Eurostat 2019).

Moldova is characterized through a high level of mortality in the working-age population that mostly maintain low life expectancy at birth compared to West European countries (Gagauz et al. 2016). However, in the last two decades, a slow but steady growth trend in life expectancy at birth has been recorded. The substantial parts of noted gains in life expectancy in that period are determined by reductions in avoidable mortality (Stirba, Pahomii 2019). On the other hand, the level of premature and avoidable mortality remains higher comparative with other European countries and it is noted a significant gap between sexes (Pahomii 2018; Gagauz, Onofrei, Pahomii 2019).

Both nationally and internationally, there are studies aimed at estimating losses and indirect costs caused by premature mortality. The economic losses due to premature mortality are estimated at subnational-regional (Etco, Pantea, Cernelea 2011; Sukhoveyeva, Komarova 2015), national (Carter, Schofield, Shrestha 2017; Gagauz, Onofrei, Pahomii 2019) and international level - for comparison between countries (Menzin et al. 2012). It is important to state that worldwide overall premature mortality, as well as economic losses linked with them, are several times high in males than in females (Etco, Pantea, Cernelea 2011; Carter, Schofield, Shrestha 2017; Ryngach 2016; Pahomii 2018; Gagauz, Onofrei, Pahomii 2019). Also, the top causes of death that determine the highest economic losses are represented by CVD (cardiovascular diseases), neoplasm and external causes of death (Etco, Pantea, Cernelea 2011; Díaz-Jiménez et al. 2015; Gagauz, Onofrei, Pahomii 2019). There are a lot of studies that analyse these causes separately because of the great economic impact that they had, both regarding direct and indirect economic costs (Kontsevaya, Kalinina, Oganov 2013; Hanly, Sharp 2014; Hanly, Soerjomataram, Sharp 2015; Pearce et al. 2018; Carter, Schofield, Shrestha 2019). Even if different aspects of premature mortality and related economic costs are well studied, the aspect of avoidable mortality in this field is overlooked. A team of Colombian researchers presents an important work in this area. Díaz-Jiménez et al. (2015) estimated that avoidable mortality has a huge economic impact from the lost productivity perspective, equivalent to between $1.6 \%$ and $3.0 \%$ of the annual GDP. The researchers created two distinct scenarios for the estimation of economic losses due to avoidable mortality based on average wage and annual GDP (Díaz-Jiménez et al. 2015).

The relevance of the paper. It is important to highlight that premature, as well as avoidable mortality, constitute important social and economic losses for society (Menzin et al. 2012; Hanly, Soerjomataram, Sharp 2015; Łyszczarz 2019), analysed both as present and as potential economic losses. Considering the high level of premature mortality in Moldova (Pahomii 2018), the studying of avoidable mortality represents a subject of major interest. The estimation of the size of the economic equivalent of irremediable losses caused by premature and avoidable deaths will allow assessing the potential economic damage to national development.

The aim of the article and innovation character. Most of the studies, both at the national and international levels, are focused on costs and economic losses due to premature mortality. However, the economic impact, from the perspective of indirect economic costs, of avoidable mortality for Moldova was overlooked. In order to cover this gap, this study is aimed to estimate the share and structure of avoidable mortality in total indirect economic costs of premature mortality, using the human capital approach and to highlight discrepancies between sexes.

Research questions. This study is designed to answer the following research questions:

- What was the proportion of avoidable mortality in overall premature mortality in Moldova, in the period 2014-2016?

- What is the indirect cost of avoidable mortality concerning the annual GDP in Moldova in the analysed period? 
- What causes have the highest economic impact in the structure of avoidable mortality in Moldova in the period between 2014-2016 years?

Conceptual framework of the study. In this study, we used the human capital approach to estimate the value of productivity lost due to total premature mortality and of avoidable causes of death. This approach is based on the hypothesis that each person contributes to the productivity of society. Accordingly, the human capital approach relates to unrealized income or the value of potential products lost due to illness or premature death (Boccuzzi 2003). Although this theory is widely used in the literature, there are some criticisms and the main one is the overestimation of economic losses due to premature or avoidable mortality (Birnbaum 2005; Perace et al. 2014), because it assumes equivalent contribution to each member of society. However, there are some important strengths - simple and transparent methodology to value lost productivity. The main argument to use that approach was the availability of data.

\section{Data and methods}

The population age and sex distribution, as well as economic indicators, were provided by the National Bureau of Statistics. As economic indicator was used GDP per capita. Data for 2014-2016 was used due to the revised number of the population. Starting with 2014 NBS (National Bureau of Statistics) presented the revised number of population - present population. The population with usual residence or present population represent the number of the population who preponderantly last 12 months lived on the territory of Moldova indifferent of temporary absence. The methodology of calculation of present population assumes excluding of long-term emigrants, this who are absent from the territory of the country more than 12 months (Statistics 2020). The starting year is determined by the Population and Housing Census of the 2014 year.

To allow comparability through time and to bring more clarity we have converted national GDP per capita to constant $\$$ US, the year 2017 value $(1 \$=18.499$ MDL). The use of constant values for converting national currency (MDL) to \$US allow us to exclude conversion shocks throughout the analysed period (2014-2016 years). The year 2017 was chosen mainly arbitrary, however, the \$US value is used as constant for some World Bank Database indicators.

For premature mortality, the set threshold was 65 years. In the literature from the field different thresholds are discussed which define death as a premature one (Lapostolle et al. 2008; The Conference Board of Canada 2015; OECD/Eurostat 2019). In this regard, OECD proposed as threshold the age of 75 (OECD/ Eurostat 2019), however, earlier OECD operated with the 70-year threshold (The Conference Board of Canada 2015). The set of the specific threshold depends mainly on observed level of mortality and interest of the researcher (Wise et al. 1988; Mingot, Rue, Borrell 1991; Pham, Shack, Cheung 2019). In our case because of the lower level of life expectancy at birth compared with OECD countries the threshold of 65 years was chosen.

The mortality data were provided by the WHO Mortality Database, where data are available at a very low disaggregation level and on 5-year age-groups and sexes. To determine the avoidable causes of death we need the disaggregation of data on the 3-digit level. The data regarding causes of death presented on the NBS page are available just for broad categories of causes and do not allow to highlight avoidable causes of death. Data can be obtained just through an official request from the Ministry of Health, Labour and Social protection, but that could take a long time of waiting. At the moment of writing, the cause of death data provided by WHO Mortality Database, therefore, represent the most recent data available at the needed level of disaggregation. For the classification of avoidable mortality, the list of ICD, Tenth Revision causes defined in the report of OECD (OECD/Eurostat 2019) was used.

For total premature deaths and broad causes of avoidable death groups, the Potential Years of Life Lost (PYLL) were estimated. The PYLL is a very useful indicator because it considers the impact of premature deaths, by putting more importance on deaths occurring in the youngest ages (Lapostolle et al. 2008). PYLL is defined as the number of years of life lost by persons who died before the specified age limit and is measured in person-years (Šemerl, Šešok 2002). Other authors had defined the PYLL as the indicator which allows estimating the average time a person would have lived if he/she had not died prematurely (Gardner, Sanborn 1990). The PYLL is constructed by the weighting of each death by the number of years between the age at death and the set threshold. The used formula for PYLL calculation is presented below:

$$
\begin{aligned}
& P Y L L=\sum_{i=1}^{64} d_{i} a_{i} \\
& a_{i}=65-x_{i}
\end{aligned}
$$

In the above formula, $a_{i}=$ remaining years of life until the upper limit of age (in this case, 65 years); $d_{i}=$ number of observed deaths in each class interval; $i=$ the mid-point of age interval.

In the present study, we carried out the cost-analysis of the total premature mortality and avoidable causes of death. It is important to mention that our study is based on the Human Capital Approach. The Human Capital Approach assumes that the economic impact will be equal for all lifetime outputs and also this approach equalise the economic contribution of each society member (Boccuzzi 2003). We have 
focused just on indirect economic losses. In his work, Boccuzzi has defined that indirect economic costs of mortality represent the present value of future earnings lost by those individuals who die prematurely (Boccuzzi 2003). In order, to assess the indirect economic losses due to premature and avoidable mortality the observed PYLL was multiplied by GDP per capita. The used formulas for calculation of indirect economic losses are presented below:

$$
\begin{aligned}
I E L & =\sum_{i, j} P Y L L_{i, j} \times G D P \text { per capita } \\
I E L & =\sum_{i, j}^{c} P Y L L_{i, j}^{c} \times G D P \text { per capita }
\end{aligned}
$$

In the above formulas, $I E L=$ Indirect Economic Losses; $i=$ age-group; $j=\operatorname{sex} ; c=$ cause of death.

The broad causes of avoidable death groups used in analysis correspond to that proposed by OECD (OECD/Eurostat 2019). In this research, were analysed the following broad causes of death: infections, neoplasms, CVD, diseases of the respiratory system, diseases of the digestive system, injuries, alcohol-related and drug-related deaths and other causes of death. Endocrine and metabolic diseases, diseases of the nervous system, diseases of the genitourinary system, pregnancy, childbirth and perinatal period, congenital malformations and adverse effects of medical and surgical care were classified in other causes of death group. The last causes classified in a broad group of other causes registered a small number of events, this became the main argument in that grouping.

\section{Main results and findings}

Premature mortality represents an important issue for Moldova. Half of all deaths registered for males in the analysed period (2014-2016) represent premature deaths (deaths before 65 years). For female at the set threshold of 65 years are observed the quarter of all deaths registered during that period (Pahomii 2018). Another alarming fact is the stagnation of the premature mortality in the analysed period. In accordance with released calculation was observed slight fluctuation upwards and downwards, which does not change essentially the situation. The estimated PYLL in the general population in 2014 was 8513.1 person-years per 100 thousand population aged $0-64$, in 2015 it registered insignificant soar to 8606.8 person-years per 100 thousand population and in 2016 was noted an averting to 8284.8 person-years per 100 population. The PYLL registered for males, throughout all the analysed period, was more than two times higher than for females.

The age distribution of PYLL shows the age groups with the highest contribution (Fig. 1). PYLL puts more importance on young ages, because of that PYLL for infant mortality had a pretty high level, even in comparison with other age-groups, especially for females. For all analysed years (2014-2016) PYLL at age 0 for females exceeded the PYLL registered for other agegroups, and just 50-54 and 55-59 age-groups PYLL approached to this level. It is important to mention that in 2016 the PYLL of females was lower for most

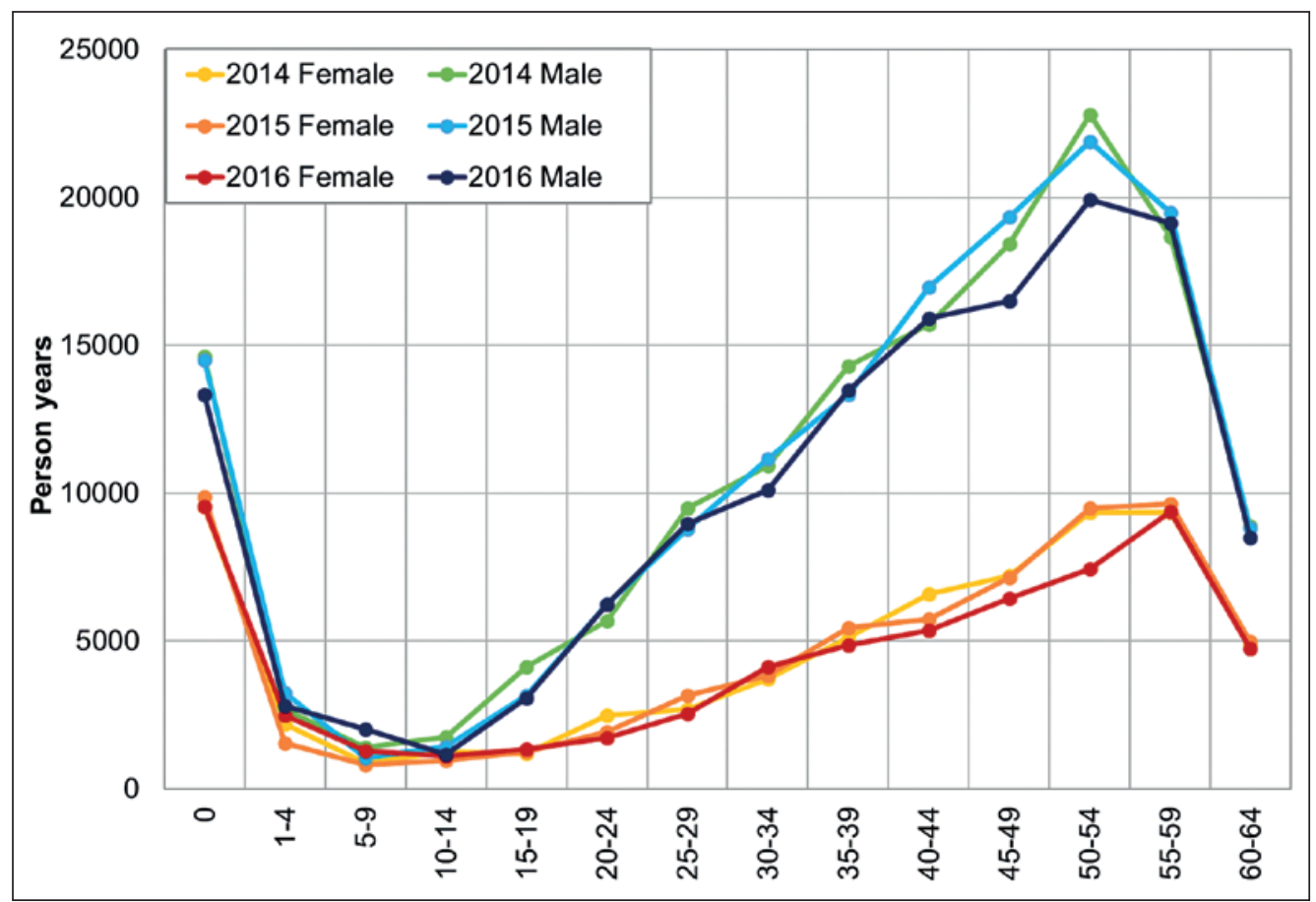

Fig. 1 PYLL by sex and age-groups, 2014-2016.

Source: Author calculation 


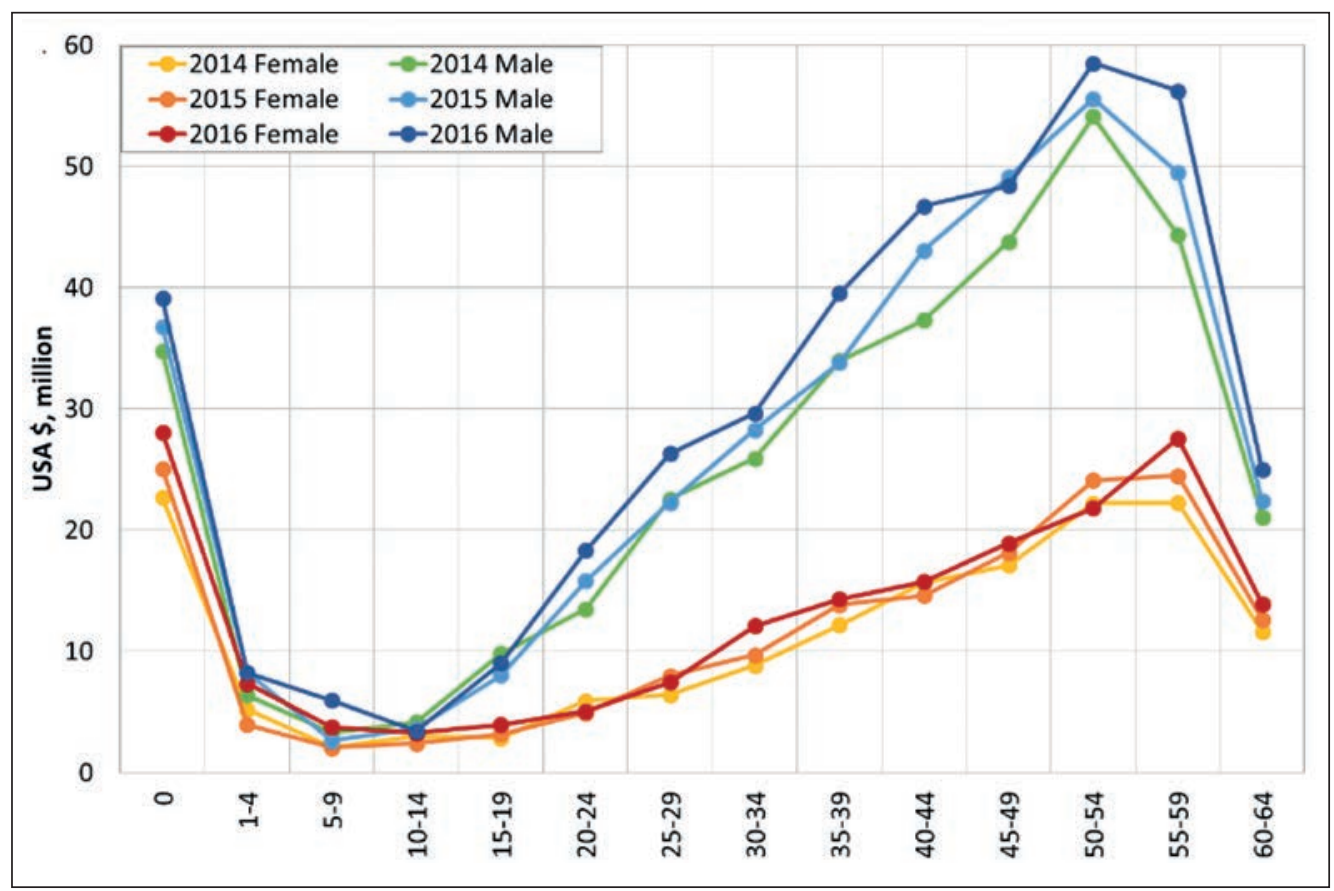

Fig. 2 Total indirect economic costs of premature mortality by age-groups and sexes, 2014-2016.

Source: Author calculation

age-groups, as a result just 55-59 age-group come close to the level of 0 years. The highest level of PYLL for infant deaths is due to the large difference to a threshold, while the peak in 50-54 and 55-59 agegroups is determined by the greater number of deaths observed. Due to the high level of male mortality, the PYLL for 40-59 age-groups overtakes the PYLL for infant mortality. The low level of PYLL registered for last age-group (60-64 years) is determined by the small differences between the mean of age interval and settled threshold.

The age structure of male PYLL repeats the discrepancies observed at a general level between sexes. The male PYLL exceeds the female one by 1 to 3.6 times depending on age-group. In this regard is important to mention that the highest differences between male and female PYLL are observed in 2014 in 15-19, 25-29 age-groups ( 3.4 and 3.5 times), in 2015 in 20-24 and 40-44 age-groups (3.2 and 3.0 times) and 2016 in 20-24, 25-29 and 40-44 age-groups (3.6, 3.5 , and 3.0 times). It is important to mention that the lowest differences are recorded for youngest agegroups. Up to 15 years, the highest difference between male and female PYLL is 1.6 times.

In the figure below is presented the potential economic damage determined by indirect economic costs of premature mortality. That costs were estimated through the multiplication of PYLL by GDP per capita. The absolute value of economic losses due to premature mortality as well as indirect costs of avoidable mortality grew throughout the analysed period from 512.9 million \$ in 2014 to 597.7 million \$ in 2016 and from 454.1 million $\$$ in 2014 to 511.4 million $\$$ in
2016 respectively. The growth of the absolute value of total indirect economic costs of premature mortality and avoidable causes of death is mainly caused by the growth of GDP per capita in the analysed period. Reported to the annual GDP and analysed like shares the indirect economic costs seem to be constant. The potential economic losses due to premature mortality were equivalent to $7.6 \%$ of the annual GDP in 2014 and recorded an insignificant decrease of $0.3 \%$ in 2016 to $7.3 \%$. Thirds of the total economic losses due to premature mortality are determined by female PYLL, while $70 \%$ refer to males (Fig. 2). Economic losses due to premature mortality for infant deaths are at a relatively high level for both sexes and drop for next 4 age-groups. For females, there is another peak in the 55-59 age-group, but this does not exceed the first peak for infant mortality. Another peak in males is registered in the 50-54 age-group, but economic losses due to premature mortality of infants are exceeded starting with 35-39 age-group.

The costs of avoidable mortality in total indirect economic losses due to premature mortality represent $85 \%$ in female in 2014 and are reduced to $83.8 \%$ in 2016 (Fig. 3). In males, the share of the costs of avoidable mortality in total indirect economic losses due to premature mortality is slightly higher - represented $87.7 \%$ in 2014 and is reduced to $86.3 \%$ in 2016. An alarming fact is that the proportion of indirect economic losses due to avoidable causes of death is the same for both sexes. So even if we have significant discrepancies in absolute values by sexes, the relative structure of losses due to avoidable and non-avoidable causes of death is mainly the same for 


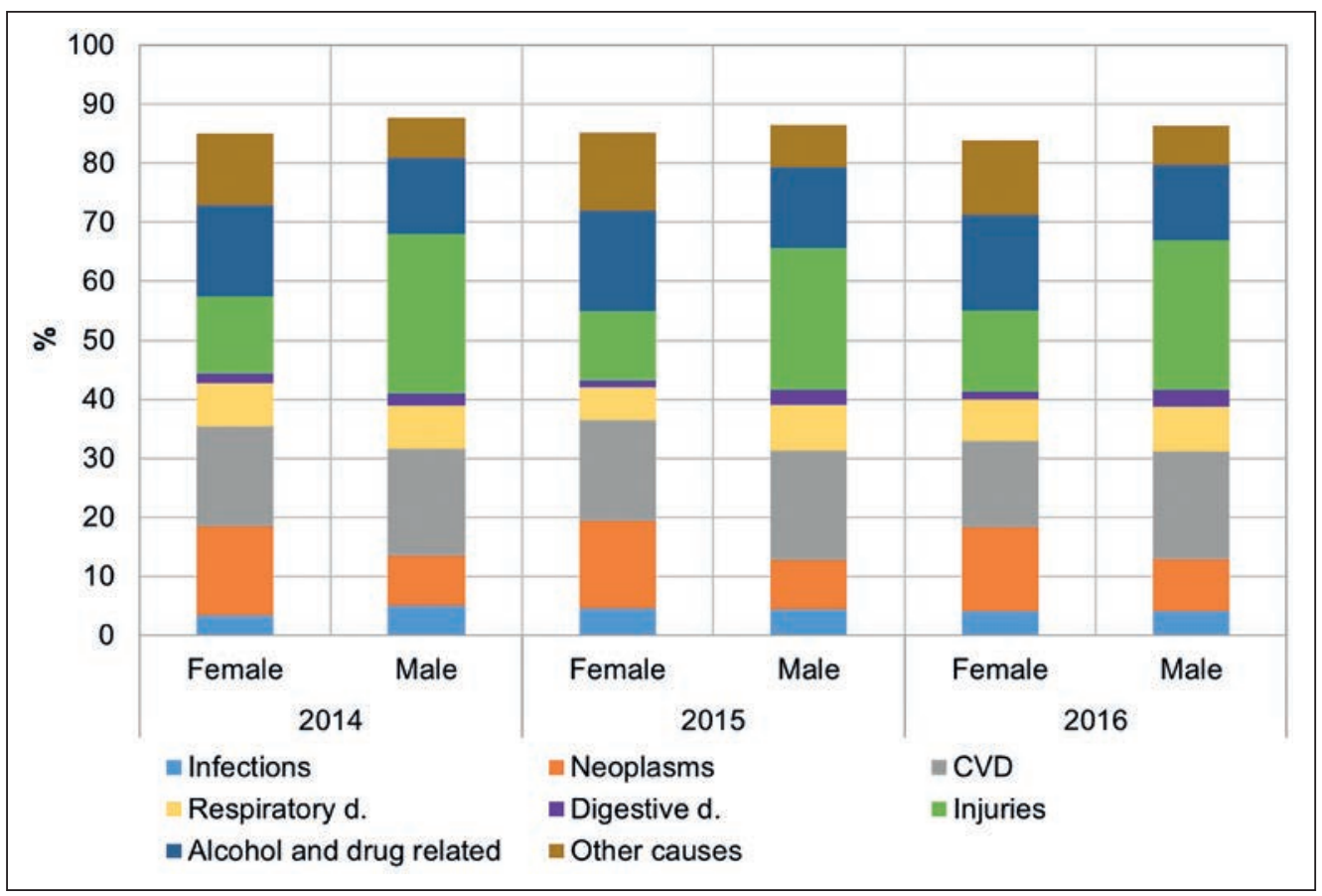

Fig. 3 Share of economic losses due to avoidable mortality in total economic losses due to premature mortality by major causes of death and total, by sexes, 2014-2016.

Source: Author calculation

both - males and females. These significant losses represent an important potential which can be saved if needed activities will be done in the light to averted avoidable mortality. In this order of ideas is important to state that structure of avoidable mortality by causes of death become very important.

From the perspective of the structure of mortality by broad causes of death, analysed for both sexes, the highest costs corresponded to injuries (21.6\% of total avoidable mortality costs), CVD (17.6\%), alcohol and drug-related (14\%), neoplasms (10.5\%), the remaining causes of death account for $22 \%$ (infections, respiratory disease, digestive disease, other causes). The structure of avoidable mortality is different for males and females. Top five avoidable causes of death in the structure of indirect economic losses due to premature mortality in males are injuries, CVD, alcohol and drug-related deaths, neoplasms and respiratory diseases; while in females, are observed other classification: alcohol and drug-related deaths, CVD, neoplasms, injuries and other causes of death. Among both males and females, these five main causes of death account for two-thirds of all economic losses due to premature mortality.

The gender gap is not observed if data are analysed like shares from total indirect costs due to premature mortality, it became pronounced when indirect costs of avoidable mortality are analysed toward annual GDP (Tab. 1). The total indirect costs of avoidable mortality are 2.3 times higher in males compared to females throughout all analysed period. The lower gender gap is observed for avoidable mortality from other causes of death and neoplasms while the highest is observed in injuries and mortality due to the digestive system diseases. The indirect cost of avoidable mortality due to other causes of death and neoplasms are on average 1.2 and 1.3 times respectively higher in males compared with females. The avoidable mortality due to injuries and to the digestive system diseases are on average, for the analysed period, 4.5 and 4.3 times more costly for males than for females. The indirect costs of avoidable mortality due to CVD, the respiratory system diseases and infections are on average 2.6 times higher in males in comparison with females. The discrepancies in alcohol-related and drug-related mortality is a little lower -1.8 times higher in males. The indirect costs are higher in males because of their higher level of premature avoidable mortality.

The indirect economic costs related to female avoidable mortality represented in $20142.11 \%$ from the annual national GDP and in 2016 reduced to $1.87 \%$; in absolute terms, the indirect economic losses represent 143 million \$ and 153.7 million \$. In the males, the losses are even higher and represent 311.1 million \$ in 2014 and 357.7 million \$ in 2016. In the females, 4 leading avoidable causes of death CVD, alcohol and drug-related deaths, neoplasms and injuries - in 2014 determined 66.4\% (95 million \$) of indirect economic costs. It is important to state that in 2016 these causes remained also actual and determined approximative 70\% (107 million \$) of indirect economic costs related to avoidable mortality. In the males, the same 4 leading causes are observed, but 
Tab. 1 The indirect costs of avoidable mortality, share from the annual GDP (\%), by broad causes of death, year and sexes.

\begin{tabular}{|l|c|c|c|c|c|}
\hline \multirow{2}{*}{ Causes of death } & \multicolumn{2}{|c|}{2014} & \multicolumn{3}{c|}{2015} \\
\cline { 2 - 6 } & Females & Males & Females & Males & Females \\
\hline Infections & 0.08 & 0.26 & 0.11 & 0.23 & 0.09 \\
\hline Neoplasms & 0.35 & 0.45 & 0.34 & 0.44 & 0.32 \\
\hline CVD & 0.39 & 0.94 & 0.40 & 0.98 & 0.32 \\
\hline Digestive system diseases & 0.17 & 0.39 & 0.13 & 0.41 & 0.16 \\
\hline Respiratory system diseases & 0.04 & 0.11 & 0.03 & 0.13 & 0.03 \\
\hline Injuries & 0.30 & 1.41 & 0.27 & 1.28 & 0.31 \\
\hline Alcohol-rel. and drug-rel. d. & 0.36 & 0.67 & 0.40 & 0.71 & 0.36 \\
\hline Other causes & 0.41 & 0.35 & 0.31 & 0.38 & 0.38 \\
\hline Total & 2.11 & 4.59 & 1.98 & 4.56 & 0.28 \\
\hline
\end{tabular}

Source: Author calculation

these are different ranged. So, the most indirect economic losses are determined by injuries, CVD, alcohol and drug-related deaths and neoplasms. These 4 causes defined, in 2014, 75\% (233.3 million \$) of indirect economic costs related to male avoidable mortality. The share of these 4 leading causes remained the same in the 2016, but in absolute values is higher 270.4 million $\$$ - because of higher absolute indirect economic losses due to male avoidable mortality. The fact that the same leading causes was observed in both, females and males, highlight that existing problems are mainly the same in both. This also shows the priority domains for interventions.

\section{Conclusions}

Economic losses due to premature mortality are twice higher for males compared to females. This is determined, mainly by a higher level of premature mortality registered for males. In this context, it is important to note that despite the high gap in the level of premature mortality between sexes the share of avoidable deaths is mainly the same in the structure of total economic losses due to premature mortality for both. The indirect costs of avoidable mortality represent slightly over $85 \%$ of total economic losses due to premature mortality.

The analysed period is too short to be able to identify stable trends in the development of the situation. It is important to note that even if indirect economic costs by broad avoidable causes of death, expressed in absolute values, rise in the 2014-2016 period, their share related to annual GDP remains the same. That fact allows us to conclude that in the 2014-2016 period indirect economic costs of avoidable mortality remained mainly constant.

The economic losses due to avoidable mortality are very significant for Moldova, especially due to injuries, CVD and alcohol and drug-related deaths. The reduction of the occurrence of these causes can diminish not only the productivity loss but also other costs related to them: reduction of costs related to treatment and other indirect costs before death.

Even if there are controversies regarding the human capital approach the obtained results are important mainly for prioritization of public health interventions. The results of the study can be used for a further cost-benefit analysis to select more economic effective potential intervention.

Different structure of avoidable mortality between males and females require targeted interventions for solving the most acute problems of both. In males, the most economic losses are determined by injuries, whereas in females are observed two causes which determined highest economic losses - CVD and alcohol and drug-related deaths.

The future work will be focused on detailed analysis of the individual avoidable causes of death and a longer period will be studied.

\section{Acknowledgements}

This research was supported by the project within the State Program (2020-2023) 20.80009.0807.21 "Migration, demographic change and stabilization policies" (National Agency for Research and Development, Moldova). I also would like to thank the two anonymous reviewers for the comments and suggestion which allow to improve and strengthen this paper.

\section{References}

Australian Institute of Health and Welfare. (2016): Australia's health series no. 15. Cat. no. AUS 199. Canberra: AIHW. Canberra: AIHW. Retrieved from https://www.aihw.gov.au/getmedia/2cea81f2-7de5 -4307-85b7-9f84cd12981c/ah16-3-2-premature -mortality.pdf.aspx.

Average exchange rate. (2017): Retrieved from National Bank of Moldova Web site: https://www.cursbnm.md /curs-valutar-mediu-lunar-bnm. 
Birnbaum, H. (2005): Friction-cost method as an alternative to the human-capital approach in calculating indirect costs. Pharmacoeconomics 23, 103-104, https://doi .org/10.2165/000190053-200523020-00001.

Boccuzzi, S. (2003): Indirect health care costs. In W. Weintraub, Cardiovascular health care economics. New Jersey: Humana Press, https://doi.org/10.1007 /978-1-59259-398-9_5.

Carter, H., Schofield, D., Shrestha, R. (2017): The long-term productivity impacts of all cause premature mortality in Australia. Australian and New Zeeland Journal of Public Health 41(2), 137-143, https://doi.org/10.1111 /1753-6405.12604.

Carter, H., Schofield, D., Shrestha, R. (2019): Productivity costs of cardiovascular disease mortality across disease types and socioeconomic groups. Open Heart 6(1): e000393. https://doi.org/10.1136/openhrt-2018 $-000939$.

Díaz-Jiménez, D., Castañeda-Orjuela, C., Castillo-Rodríguez, L., Hoz-Restrepo, F. (2015): Economic costs analysis of the avoidable mortality in Colombia 1998-2011. Value in Health Regional Issue 8, 129-135, https://doi.org /10.1016/j.vhri.2015.08.007.

Etco, C., Pantea, V., Cernelea, D. (2011): Medical, social and economic burden of Potential Years of Life Lost (PYLL) as a result of deaths in the working age population (in Romanian). Public Health, Economy and Management in Medicine 5(40), 26-30. Retrieved from http://public -health.md/uploads/docs/reviste/CM5_40_2011.pdf.

Gagauz, O., Onofrei, N., Pahomii, I. (2019): Economic costs of premature mortality in Republic of Moldova (in Romanian). Journal of Philosophy, Sociology and Political Science 3(181), 119-133.

Gagauz, O., Stratan, A., Buciuceanu-Vrabie, M., Penina, O., Ciubotaru, V., Cheianu-Andrei, D. (2016): Population situation analysis in the Republic of Moldova. Chisinau: National Institute for Economic Research. Retrieved from https://moldova.unfpa.org/sites/default/files /pub-pdf/PSA_engleza.pdf.

Gardner, J., Sanborn, J. (1990): Years of potential life lost (YPLL) - what dose it measure? Epidemiology, 322-329. Retrieved from https://journals.lww.com/epidem/ Abstract/1990/07000/Years_of_Potential_Life_Lost _YPLL_What_Does_it.12.aspx.

Hanly, P., Sharp, L. (2014): The cost of lost productivity due to premature cancer-related mortality: an measure of the cancer burden. BMC Cancer 14(224), https://doi.org /10.1186/1471-2407-14-224.

Hanly, P., Soerjomataram, I., Sharp, L. (2015): Measuring the social burden of cancer: The cost of lost productivity due to premature cancer-related mortality in Europe. International Journal of Cancer 136: E136-E145, https://doi.org/10.1002/ijc.29105.

Holland, W. (1997): European comunity Atlas of "Avoidable Death" 1985-1989. (W. Holland, Ed.) Oxford: Oxford University Press.

Joel, G. R. (2017): Editorial Reducing premature mortality among young and middle-aged adults. Health Promotion and Chronic Disease Prevention in Canada: Research, Policy and Practice 37(3), 27-32. Retrieved from https://www.ncbi.nlm.nih.gov/pmc/articles /PMC5602160/.

Kontsevaya, A., Kalinina, A., Oganov, R. (2013): Economic burden of cardiovascular diseases in the Russian
Federation. Value in Health Regional Issues 2(2), 199-204, https://doi.org/10.1016/j.vhri.2013.06.010.

Lapostolle, A., Lefranc, A., Gremy, I., Spira, A. (2008): Premature mortality measure: Comparison of deaths before 65 years of age and expected years of life lost. Revue d'Épidémiologie et de Santé Publique 56(4), e1-e7, https://doi.org/10.1016/j.respe.2008.07.001

Łyszczarz, B. (2019): Production losses associated with premature mortality in 28 European Union countries. Journal of Global Health 9(2), e:020418, https://doi.org /10.7189/jogh.09.020418.

Menzin, J., Marton, J. P., Menzin, J. A., Wilke, R. M., Federico, V. (2012): Lost productivity due to premature mortality in developed and emerging countries: an application to smoke cessation. BMC Medical Research Methodology 12(87), https://doi.org/10.1186 /1471-2288-12-87.

Mingot, M., Rue, M., Borrell, C. (1991): The years of potential life lost: comparison of three methods of calculation. Gaceta Sanitara 5(22), 21-28, https://doi.org/10.1016 /S0213-9111(91)71045-5.

Nolte, E., McKee, M. (2004): Does health care save lives? Avoidable mortality. London: The Nuffield Trust.

OECD/Eurostat. (2019): Avoidable mortality: OECD /Eurostat lists of preventable and treatable causes of death (November 2019 version). Retrieved from https://www.oecd.org/health/health-systems /Avoidable-mortality-2019-Joint-OECD-Eurostat-List -preventable-treatable-causes-of-death.pdf.

Pahomii, I. (2018): Dynamic of premature mortality in last two decade: comparative study Republic of Moldova-Estonia. "Economic growth in the conditions of globalization: competitiveness, innovation, sustainability". International scientific-practical conference 13, 45-56. Chisinau.

Pearce, A., Sharp, L., Hanly, A., Barchuk, A., Bray, F., Cancela, M., ..., Soerjomataram, I. (2018): Productivity losses due to premature mortality from cancer in Brazil, Russia, India, China and South Africa (BRICS): A populationbased comparison. Cancer Epidemiology 53, 27-34, https://doi.org/10.1016/j.canep.2017.12.013.

Perace, A., Timmons, A., Hanley, A., O'Neil, C., Sharp, L. (2014): Comapring the Human capilat and Friction cost approaches to estimating productivity costs. Retrieved from https://www.researchgate.net/publication /272817571_Comparing_the_Human_Capital_and _Friction_Cost_approaches_to_estimating_productivity _costs.

Pham, T.-M., Shack, L., Cheung, W. Y. (2019). Introduction of a novel measure of premature mortality caused by chronic condition: real-world examples from prostate and testis cancers in Canada, 1980-2015. Annals of Epidemiology 37, 81-83, https://doi.org/10.1016 /j.annepidem.2019.07.011.

Ryngach, N. (2016): Economic equivalent of losses due to premature mortality in Ukraine. Demography and Social Economy 2(27), 39-49, https://doi.org/10.15407 /dse2019.04.

Šemerl, J. Š., Šešok, J. (2002): Years of Potential Life Lost and Valued Years of Potential Life Lost in Assessing Premature Mortality in Slovenia. Croatian Medical Journal 43(4), 439-445.

Statistics, N. B. (2020): Metadata. Population and demography. Retrieved from National Bureau of 
Statistics: https://statistica.gov.md/public/files /Metadate/Populatia.pdf.

Stirba, V., Pahomii, I. (2019): The contribution of avoidable mortality to the life expectancy change in the Republic of Moldova. Demography and Social Economy 4(38), 58-72, https://doi.org?10.15407 /dse2019.04.

Sukhoveyeva, A., Komarova, T. (2015): Nekotorye aspekty ekonomicheskoy otsenki poter' zdorov'ya v rezul'tate smertnosti naseleniya Dal'nego Vostoka Rossii.
Sotsial'nyye aspekty zdorov'ya naseleniya. Retrieved from http://vestnik.mednet.ru/content/view/633/30/. The Conference Board of Canada. (2015): Premature mortality. Retrieved from https://www.conferenceboard .ca/hcp/provincial/health/premature.aspx.

Wise, R., Livengood, J., Berkelman, R., Goodman, R. (1988): Methodological alternatives for measuring premature mortality. American Journal of Preventive Medicine 4(5), 268-273. Retrieved from https://www.sciencedirect .com/science/article/pii/S0749379718311607\#. 